\title{
Virtual Reality Community Gait Training Using a 360 Image Improves Gait Ability in Chronic Stroke Patients
}

\author{
Myung-Joon Kim \\ Department of Physical Therapy, College of Health Science, Kyungdong University, Wonju, Korea
}

Purpose: Gait and cognitive impairment in stroke patients exacerbate fall risk and mobility difficulties during multi-task walking. Virtual reality can provide interesting and challenging training in a community setting. This study evaluated the effect of community-based virtual reality gait training (VRGT) using a 360-degree image on the gait ability of chronic stroke patients.

Methods: Forty-five chronic stroke patients who were admitted to a rehabilitation hospital participated in this study. Patients meeting the selection criteria were randomly divided into a VRGT group $(n=23)$ and a control group $(n=22)$. Both these groups received general rehabilitation. The VRGT group was evaluated using a 360-degree image that was recorded for 50 minutes a day, 5 days per week for a total of 6 weeks after their training. The control group received general treadmill training for the same amount of time as that of the VRGT group. The improvement in the spatiotemporal parameters of gait was evaluated using a gait analyzer system before and after training.

Results: The spatiotemporal gait parameters showed significant improvements in both groups compare with the baseline measurements $(p<0.05)$, and the VRGT group showed more improvement than the control group $(p<0.05)$.

Conclusion: Community-based VRGT has been shown to improve the walking ability of chronic stroke patients and is expected to be used in rehabilitation of stroke patients in the future.

Keywords: Stroke, Gait, Rehabilitation, Virtual reality

\section{INTRODUCTION}

Hemiplegia is a complication in stroke patients that contributes to gait dysfunction. It is characterized by a slower walking speed, inefficient gait, and lack of coordination of movements. ${ }^{1}$ The major goal of rehabilitation is restoration of the gait in the patients. ${ }^{2}$ It is essential to repeat the task walking exercise in order to facilitate the re-acquisition of motor skills. ${ }^{3{ }^{3}}$ Treadmill training is an effective exercise that improves the measures of activities of daily living and gait pattern. ${ }^{4-6}$ Additionally, adjusting the weight load while walking on the treadmill can promote coordination of the legs and improve walking speed. ${ }^{7-9}$

Gait retraining after a stroke requires exposure to various environmental conditions and situations when walking. ${ }^{10}$ Rehabilitation within the clinical practice requires patients to be exposed to vari-

Received Jun 9, 2020 Revised Jun 17, 2020

Accepted Jun 22, 2020

Corresponding author Myung-Joon Kim

E-mail kykys@kduniv.ac.kr ous environmental conditions in a small treatment room and they cannot experience community environment. Although patients can experience these conditions during the outdoor rehabilitation training, the risk of climbing stairs, various obstacles, and weather conditions are major hinderance. ${ }^{10,11}$ It is becoming increasingly popular to provide virtual reality technology to improve the environment inside and outside the treatment room. ${ }^{12-14}$

Virtual reality is used to artificially stimulate visual and proprioceptive information. ${ }^{15}$ This information simulates the real environment. ${ }^{16}$ Virtual reality allows repetitive and long-term functional retraining and exposes patients to environmental conditions by controlling the risk factors. ${ }^{17}$ In this environment, the users can expect to react to events as if they were real. Research on virtual realitybased treadmill gait training has been conducted in various ways on the stroke parents with an emphasis on interventions that reflect

Copylight $(02020$ The Korean Society of Physical Therapy

This is an Open Access article distribute under the terms of the Creative Commons Attribution Non-commercial License (https:// creativecommons.org/license/by-nc/4.o.) which permits unrestricted non-commercial use, distribution, and reproduction in any medium, provided the original work is properly cited. 
reality and include active participation. ${ }^{8,12,15}$

Integrating virtual reality into existing gait retraining can further improve gait abiity. ${ }^{18}$ The patients who participated actively in virtual reality based training had improved motor skills than those who participated in conventional task oriented interventions. ${ }^{19}$ Virtual reality enables the patients to experience spatial and temporal experiences close to the real world through a head mounted display (HMD) equipment. The patients can achieve a sense of purpose and motivation due to the interactive virtual space where community environment is implemented, and real-time feedback is received through treadmill walking. ${ }^{20}$

Although the importance of immersion in the field of rehabilitation has been emphasized and technology has been developed, most of the studies aimed at confirming the effectiveness of virtual reality intervention in stroke patients are studies using non-immersive virtual reality. ${ }^{17,21}$ The reason for the lack of research on immersive virtual reality compared to the study using non-immersive virtual reality is that non-immersive virtual reality devices have relatively good accessibility, whereas initial immersive virtual reality devices have low resolution, insufficient drive rate, and cybersickness. However, recently, due to advances in HMD technology, limitations such as resolution, driving rate, and cybersickness can be solved to provide a more realistic and realistic virtual environment. ${ }^{22}$ In various fields such as education, tourism, and medical care studies using immersive virtual reality with advanced technology are gradually increasing, and based on those studies, a lot of actual contents are also being developed. In the field of rehabilitation, research is needed to confirm the effectiveness of training using immersive virtual reality with improved technology.

In this study, the goal was to confirm the impact of community based virtual reality gait training (VRGT) using a 360-degree image HMD on the biomechanical gait ability of stroke patients.

\section{METHODS}

\section{Subjects}

The patients who were admitted to H Hospital, Gyeonggi due to chronic stroke for over 6 months participated in the rehabilitation program. Inclusion criteria for these patients were as follows: patients with chronic hemiplegia over a period of 6 months after stroke, patients with a mini mental state examination-Korean
(MMSE-K) of 24 or higher, patients who could participate in exercise program by understanding and implementing oral instructions, and patients with a Brunnstrom Motor recovery stage of 4 or higher. Exclusion criteria were as follows: individuals diagnosed with other abnormalities of the nervous and musculoskeletal systems; balance sensory disorders or cerebellar diseases; vision defects; or deafness. The patients were given detailed information about the purpose, procedures, and precautions of this study. They gave written consent prior to their participation in accordance with the ethical principles of the Helsinki Declaration.

The study used a randomized controlled trial design and the assessors were blinded. The sample size was determined by setting the alpha error of 0.05 and the power probability of 0.8 . Additionally, the effect size was set to 0.9 based on the gait velocity value that was revealed in the pilot experiment. Therefore, 21 patients were needed per group. A dropout rate of $10 \%$ would result in 23 participants. The sample size was calculated using the statistical power analysis program $G^{\star}$ Power version 3.1.9.7. ${ }^{23}$

\section{Experimental methods}

1) Procedure

Fifty-nine patients from Gyeonggi-do H Hospital were enrolled in this study and 11 of them were excluded. Eleven patients belonged to the exclusion criteria and 3 of them refused to participate. 45 chronic stroke patients who met the selection criteria were randomly assigned to the VRGT group $(n=23)$ and control $(n=22)$ group. A randomly assigned software program minimized the selection bias. ${ }^{24}$ The VRGT group performed virtual training 5 times per week for 6 weeks. Subjects in the VRGT group used a $360^{\circ}$ image to perform virtual reality community gait training for 50 minutes a day, 5 days a week, for 6 weeks, and the control group performed gait training without virtual reality for 50 minutes a day, 5 days a week, for 6 weeks. The general characteristics and gait ability of the patients were evaluated by two blind assessors of the training group. All the patients participated in post-evaluation and data were analyzed (Figure 1).

\section{2) Measurement}

GAITRite system (GAITRite, CIR system Inc.) is a reliable and valid tool for assessing spatial gait and foot pressure distribution in an objective manner (New Jersey, USA, 2008). ${ }^{25,26}$ The system consti- 


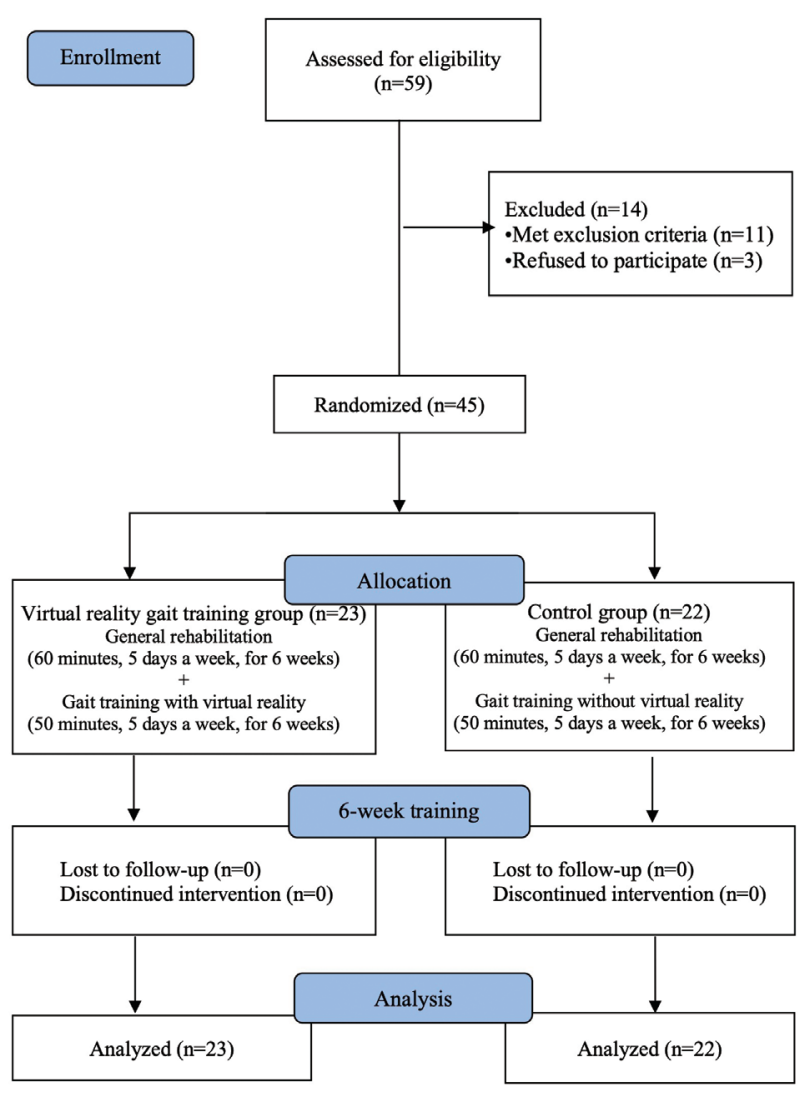

Figure 1. Flow diagram based on CONSORT.

tutes an electronic walking mat having a total length of $488 \mathrm{~cm}$, sensor of length a sensor $366 \mathrm{~cm}$, and a width of $61 \mathrm{~cm}$. The electronic mat has a total of 18,432 detection sensors and $48 \times 384$ sensors are arranged per 1.27 in diameter. When the patient walks on the mat, the sensor senses pressure of the foot and transmits this information to the computer via a serial interface cable. The pressure of the patient's foot is recorded by the gait analyzer at a sampling rate of $80 \mathrm{MHz}$ per second and transmits this information to a personal computer through a serial interface cable. Information on the temporal and spatial variables was processed by GAITRite GOLD version 32b (GAITRite GOLD, CIR System Inc., New Jersey, USA) software. After receiving a verbal signal from the tester, the patient walked at a normal speed on the walking plate and recorded data of $3 \mathrm{~m}$ in the middle of a total of $5 \mathrm{~m}$. The examiner monitored this test. Temporal parameters were gait velocity, cadence, stride time, and step time and spatial parameters were stride length and step length. For the step time and step length, the average values of both sides were used. The average of the values recorded by repeating measurements three times was used as the measured value.
3) Virtual reality gait training (VRGT)

In this study, a 360-degree camera (Insta360 ONE X, Insta360", USA) provided a virtual reality image of the community along with treadmill walking training. A total of five community videos included a $2 \mathrm{~km}$ downtown street, a shopping mall, a park, an apartment complex, and a rural area. The images also composed of the opinions of two therapists and stroke patients. Professional editors and experts produced and conducted the filming. Treadmill (JT4000, Sehan Medical, Gyeonggi-do, Korea), suspension device (TA6000, Guilin Medical, Gyeonggi-do, Korea), and head-mounted display (Oculus Rift Development Kit 2, Oculus VR, and LLC) were used. The desktop had refresh rate of $60 \mathrm{fps}, 32 \mathrm{~GB}$ simulated RAM, Intel Core i7 processor, and NVIDIA GeForce GTX 770 GPU. The resolution of the HMD was $960 \times 1,080$ pixels.

During virtual reality walking training, a suspension device that did not support weight was worn for the safety of the patients. They were allowed to walk by holding the handles of the treadmill and rested every 5 minutes to avoid cybersickness. A therapist monitored face color and checked the pulse. Normal leg braces were used. The walking speed was maintained for the safety of these patients. A total of 5 images were taken of 5 minutes each and a break of 5 minutes was provided.

\section{4) General rehabilitation training}

General rehabilitation training was conducted in both the groups. It consisted of neurodevelopmental and occupational therapy. The duration of the upper extremity exercise for neurological development was about 30 minutes and there was no direct effect on the gait.

\section{Statistical analysis}

Statistical analyses (SPSS version 18.0, IBM Corporation, Armonk, USA) of the data were carried out and expressed as mean and standard deviation. The Shapiro-Wilk test was used to determine the assumption of normality and all variables satisfied this assumption. The paired t-test compared the dependent variables, whereas the independent t-test and chi-square test compared the independent variables between the two groups. The difference of $p<0.05$ was considered statistically significant. 
Table 1. General characteristics of the patients

$(n=45)$

\begin{tabular}{|c|c|c|c|c|}
\hline & $\begin{array}{l}\text { VRGT group } \\
\qquad n=23\end{array}$ & $\begin{array}{c}\text { Control group } \\
\quad n=22\end{array}$ & $\chi^{2} / t$ & $p$ \\
\hline Age (yr) & $61.9 \pm 8.38$ & $63.55 \pm 11.06$ & 0.560 & 0.579 \\
\hline Height (cm) & $165.78 \pm 6.79$ & $162.50 \pm 9.15$ & 1.371 & 0.178 \\
\hline Weight (kg) & $62.64 \pm 6.88$ & $61.44 \pm 8.94$ & 0.508 & 0.614 \\
\hline BMI (point) & $22.79 \pm 2.13$ & $23.18 \pm 2.00$ & 0.636 & 0.528 \\
\hline Duration of stroke (month) & $15.35 \pm 7.28$ & $16.50 \pm 6.96$ & 0.542 & 0.591 \\
\hline MMSE-K & $25.83 \pm 1.37$ & $25.77 \pm 0.92$ & 0.153 & 0.879 \\
\hline Gender (male/female) & $7 / 16$ & $8 / 14$ & 0.673 & 0.178 \\
\hline Paretic side (right/left) & $10 / 13$ & $10 / 12$ & 0.458 & 0.551 \\
\hline Stroke type (Infarction/hemorrhage) & $07 / 16$ & $8 / 14$ & 0.673 & 0.178 \\
\hline
\end{tabular}

Values are expressed as mean \pm standard deviation.

BMI: body mass index, MMSE-K: mini mental state examination-Korean, VRGT: Virtual reality gait training.

Table 2. Changes in the spatiotemporal gait parameters

$(n=45)$

\begin{tabular}{|c|c|c|c|c|c|c|}
\hline Variables & & & $\begin{array}{c}\text { VRGT group } \\
n=23\end{array}$ & $\begin{array}{c}\text { Control group } \\
n=22\end{array}$ & $\mathrm{t}$ & $\mathrm{p}$ \\
\hline \multirow[t]{20}{*}{ Temporal gait parameters } & \multirow[t]{5}{*}{ Velocity (m/s) } & Pre & $0.47 \pm 0.16$ & $0.47 \pm 0.23$ & \multirow[t]{2}{*}{0.088} & \multirow[t]{2}{*}{0.930} \\
\hline & & Post & $0.57 \pm 0.19$ & $0.49 \pm 0.23$ & & \\
\hline & & Pre-Post & $0.10 \pm 0.04$ & $0.02 \pm 0.04$ & 6.317 & $<0.001^{+}$ \\
\hline & & $\mathrm{t}$ & 11.143 & 2.104 & & \\
\hline & & $\mathrm{p}$ & $<0.001^{*}$ & $0.048^{*}$ & & \\
\hline & \multirow[t]{5}{*}{ Cadence (step/min) } & Pre & $76.52 \pm 15.12$ & $75.74 \pm 16.75$ & \multirow[t]{2}{*}{0.164} & \multirow[t]{2}{*}{0.871} \\
\hline & & Post & $83.46 \pm 17.29$ & $77.74 \pm 17.89$ & & \\
\hline & & Pre-Post & $6.94 \pm 3.56$ & $2.00 \pm 3.55$ & 4.657 & $<0.001^{+}$ \\
\hline & & $\mathrm{t}$ & 9.341 & 2.658 & & \\
\hline & & $\mathrm{p}$ & $<0.001^{*}$ & $0.015^{*}$ & & \\
\hline & \multirow[t]{5}{*}{ Stride time (sec) } & Pre & $1.63 \pm 0.31$ & $1.65 \pm 0.31$ & \multirow[t]{2}{*}{0.256} & \multirow[t]{2}{*}{0.799} \\
\hline & & Post & $1.49 \pm 0.30$ & $1.61 \pm 0.31$ & & \\
\hline & & Pre-Post & $-0.13 \pm 0.07$ & $-0.04 \pm 0.07$ & 4.416 & $<0.001^{+}$ \\
\hline & & $\mathrm{t}$ & 9.381 & 2.372 & & \\
\hline & & $\mathrm{p}$ & $<0.001^{*}$ & $0.028^{*}$ & & \\
\hline & \multirow[t]{5}{*}{ Step time (sec) } & Pre & $0.81 \pm 0.16$ & $0.82 \pm 0.16$ & \multirow[t]{2}{*}{0.256} & \multirow[t]{2}{*}{0.799} \\
\hline & & Post & $0.75 \pm 0.15$ & $0.81 \pm 0.16$ & & \\
\hline & & Pre-Post & $-0.07 \pm 0.03$ & $-0.02 \pm 0.04$ & 4.416 & $<0.001^{+}$ \\
\hline & & $\mathrm{t}$ & 9.381 & 2.372 & & \\
\hline & & $\mathrm{p}$ & $<0.001^{*}$ & $0.028^{*}$ & & \\
\hline \multirow[t]{10}{*}{ Spatial gait parameters } & \multirow[t]{5}{*}{ Stride length $(\mathrm{cm})$} & Pre & $73.47 \pm 18.70$ & $71.41 \pm 21.35$ & \multirow[t]{2}{*}{0.343} & \multirow[t]{2}{*}{0.733} \\
\hline & & Post & $82.07 \pm 19.90$ & $75.94 \pm 22.31$ & & \\
\hline & & Pre-Post & $8.61 \pm 3.74$ & $4.53 \pm 7.56$ & 2.312 & $0.026^{+}$ \\
\hline & & $\mathrm{t}$ & 11.039 & 2.825 & & \\
\hline & & $\mathrm{p}$ & $<0.001^{*}$ & $0.010^{*}$ & & \\
\hline & \multirow[t]{5}{*}{ Step length (cm) } & Pre & $36.77 \pm 9.29$ & $34.72 \pm 9.98$ & \multirow[t]{2}{*}{0.714} & \multirow[t]{2}{*}{0.479} \\
\hline & & Post & $41.06 \pm 9.91$ & $37.08 \pm 10.82$ & & \\
\hline & & Pre-Post & $4.29 \pm 1.87$ & $2.37 \pm 3.86$ & 2.141 & $0.038^{+}$ \\
\hline & & $\mathrm{t}$ & 10.988 & 2.896 & & \\
\hline & & $\mathrm{p}$ & $<0.001^{*}$ & $0.009^{*}$ & & \\
\hline
\end{tabular}

Values are expressed as mean \pm standard deviation (SD).

${ }^{*}$ means significant difference within group, ${ }^{+}$means significant difference between group.

VRGT: Virtual reality gait training. 


\section{RESULTS}

Evaluation of the 23 patients belonging to the VRGT group and 22 patients belonging to the control group was carried out. There were no significant differences in patient demographics (Table 1; age, weight, height, BMI, duration of stroke, MMSE-K, gender, paretic side, and stroke type) between the groups.

Changes in the spatiotemporal gait parameters of the two groups are presented in Table 2. Intra-group analysis showed that there were significant improvements in the both groups in temporal gait parameters: the velocity, cadence, stride time, and step time $(\mathrm{p}<0.05)$. In term of velocity, the VRGT group showed significant increased from $0.47 \mathrm{~m} / \mathrm{s}$ to $0.57 \mathrm{~m} / \mathrm{s}(\mathrm{p}<0.05)$, and from $0.47 \mathrm{~m} / \mathrm{s}$ to $0.49 \mathrm{~m} / \mathrm{s}$ in control group $(\mathrm{p}<0.05)$. In terms of cadence, the VRGT group showed significant increased from $76.52 \mathrm{step} / \mathrm{min}$ to 83.46 step/min $(\mathrm{p}<0.05)$ and from $75.74 \mathrm{step} / \mathrm{min}$ to $77.74 \mathrm{step} / \mathrm{min}$ in control group $(\mathrm{p}<0.05)$. In terms of the stride time, the VRGT group showed a significant decrease from 1.63 second to 1.49 second $(\mathrm{p}<0.05)$ and from 1.65 second to 1.61 second in the control group $(\mathrm{p}<0.05)$. In terms of the step time, the VRGT group showed a significant decrease from 0.81 second to 0.75 second $(\mathrm{p}<0.05)$ and from 0.82 second to 0.81 second in the control group $(\mathrm{p}<0.05)$. In addition, in all temporal gait parameters, the VRGT group showed a more significant improvement compared to the control group $(\mathrm{p}<0.05)$. Intra-group analysis showed that there were significant improvements in the both groups in spatial gait parameters: stride length and step length $(\mathrm{p}<0.05)$. In term of stride length, the VRGT group showed significant increased from $73.47 \mathrm{~cm}$ to $82.07 \mathrm{~cm}$ $(\mathrm{p}<0.05)$, and from $71.41 \mathrm{~cm}$ to $75.94 \mathrm{~cm}$ in control group $(\mathrm{p}<0.05)$. In term of step length, the VRGT group showed significant increased from $36.77 \mathrm{~cm}$ to $41.06 \mathrm{~cm}$ ( $\mathrm{p}<0.05)$, and from $34.72 \mathrm{~cm}$ to $37.08 \mathrm{~cm}$ in control group $(\mathrm{p}<0.05)$. In addition, in all spatial gait parameters, the VRGT group showed a more significant improvement compared to the control group $(\mathrm{p}<0.05)$.

\section{DISCUSSION}

Although the human brain receives information through various sensory organs, the most important sensory experience is vision. Since more than $80 \%$ of all the information is obtained through vision and reacts sensitively to the world. Virtual reality enables hu- mans to perceive the closest view of the three-dimensional world of reality. ${ }^{16,27}$ Immersive virtual reality can be experienced anywhere emphasizing future possibilities. ${ }^{20}$ Currently, research has been very active in virtual reality and has undergone many developments that has been applied and utilized as a continuous development in the medical field. ${ }^{16}$ Immersive virtual reality enables people to experience different environments directly in a virtual space and spatial and temporal experiences that are closer to the real world through the HMD equipment. ${ }^{20,28}$ It is advantageous for the stoke patients to experience virtual reality who have difficulty in experiencing the community.

The patients could experience the community in an immersive virtual reality space and gait training confirmed its effects on stroke patients. Temporal variables such as velocity, cadence, and step time increased by $21 \%, 9 \%$, and $7 \%$, respectively. The stride time decreased significantly by $8 \%$. Two spatial variables such as stride and step lengths improved significantly by $11 \%$. Previous studies have also demonstrated that virtual reality training has a positive effect on improving the gait ability of stroke patients. ${ }^{29,30}$ In particular, it was confirmed that the combination of virtual reality and treadmill training is effective for improving the gait ability of stroke patients. ${ }^{29,30}$ In Yang et al., ${ }^{30}$ the velocity improved by $23 \%$ with a virtual reality treadmill training using animation, and this study showed similar results. Considering that walking speed is a key factor in predicting stroke mobility in the community, we believe that community based VRGT using a 360-degree image can be an effective approach to improve gait ability in chronic stroke patients. ${ }^{31,32}$ However, it is difficult to evaluate the walking speed as an indicator of return to the actual community, and the spatial and temporal gait parameters should be included as part of the evaluation. Dunsky et al. ${ }^{33}$ reported a significant improvement of $6.6 \mathrm{~cm}$ in step length by conducting community exercise imagination training for chronic stroke patients, and Yang et al. ${ }^{34}$ reported a significant improvement of $19 \%$ in stride length by conducting dual-task training in chronic stroke patients. This improvement in gait ability activated the high level center through task-oriented training and mentioned the importance of stimulating feedback through training. In this study, it is thought that the improvement of spatiotemporal gait ability was induced by providing multisensory feedback stimulation for various community environments during gait training through treadmill. 
The improvement of spatial gait parameters resulted in increase in velocity, cadence, and gait ability. This technology can recognize and focus on the gait movement because other visual information does not interfere with image that is recorded. There are changes in the brain due to the interaction between vision and proprioception. As general treadmill training involves walking in a fixed visual environment, there is a disintegration between visual and proprioception senses. ${ }^{13,16}$ In this study, the integration of vision and proprioception resulted in an improvement in gait ability. Although Lee et al. ${ }^{12}$ attempted to voluntarily change the speed through speed-interaction, the images were displayed based on the speed of treadmill that was slightly higher than the normal speed of the patients. Therefore, the spontaneous speed remained the same. Similar to this study, Cho et al. ${ }^{13}$ created a virtual reality by photographing the real world, recording, and providing an environment that was easily accessible to patients thereby improving the walking ability, participation, and motivation.

This study is significant as it presents a new environment for stroke gait rehabilitation in the age when virtual reality is being applied to various fields such as medical, education, and culture. However, despite maintaining the optical flow speed, spontaneous walking speed was not controlled in the virtual environment. Although the patients walked for shorter durations to prevent cyber-sickness, a definitive method is needed to prevent it. A quantitative and standardized therapeutic model should be constructed by incorporating augmented and mixed reality to develop gait training.

\section{REFERENCES}

1. Laborde A, Caillet F, Eyssette $\mathrm{M}$ et al. 3D preliminary analysis gait in stroke patients: knee flexion in compensatory strategies. Ann Readapt Med Phys. 2003;46(3):132-7.

2. Patterson KK, Gage WH, Brooks D et al. Evaluation of gait symmetry after stroke: a comparison of current methods and recommendations for standardization. Gait Posture. 2010;31(2):241-6.

3. Park HJ, Oh DW, Kim SY et al. Effectiveness of community-based ambulation training for walking function of post-stroke hemiparesis: a randomized controlled pilot trial. Clin Rehabil. 2011;25(5):451-9.

4. Moore JL, Roth EJ, Killian C et al. Locomotor training improves daily stepping activity and gait efficiency in individuals poststroke who have reached a "plateau" in recovery. Stroke. 2010;41(1):129-35.

5. Harris-Love ML, Forrester LW, Macko RF et al. Hemiparetic gait parameters in overground versus treadmill walking. Neurorehabil Neural Repair. 2001;15(2):105-12.
6. Song Y, Lee H. The effect of treadmill training applied simultaneously with action observation on walking ability in chronic stroke patients. J Kor Phys Ther. 2016;28(3):176-82.

7. Hesse S, Konrad M, Uhlenbrock D. Treadmill walking with partial body weight support versus floor walking in hemiparetic subjects. Arch Phys Med Rehabil. 1999;80(4):421-7.

8. Kim CH, Kim YN. Effects of proprioceptive neuromuscular facilitation and treadmill training on the balance and walking ability of stroke patients. J Kor Phys Ther. 2018;30(3):79-83.

9. Park JH, Chung YJ. Comparison of aquatic treadmill and anti-gravity treadmill gait training to improve balance and gait abilities in stroke patients. J Kor Phys Ther. 2018;30(2):67-72.

10. Fung TT, Stampfer MJ, Manson JE et al. Prospective study of major dietary patterns and stroke risk in women. Stroke. 2004;35(9):2014-9.

11. Holden MK. Virtual environments for motor rehabilitation: review. Cyberpsychol Behav. 2005;8(3):187-211.

12. Lee J, Lee K, Song C. Speed-interactive treadmill training using smartphone-based motion tracking technology improves gait in stroke patients. J Mot Behav. 2017;49(6):675-85.

13. Cho KH, Lee WH. Effect of treadmill training based real-world video recording on balance and gait in chronic stroke patients: a randomized controlled trial. Gait Posture. 2014;39(1):523-8.

14. Shin WS, Song CH. Effects of virtual reality-based exercise on static balance and gait abilities in chronic stroke. J Kor Phys Ther. 2009;21(3):3340.

15. Yang S, Hwang WH, Tsai YC et al. Improving balance skills in patients who had stroke through virtual reality treadmill training. Am J Phys Med Rehabil. 2011;90(12):969-78.

16. Lam YS, Man DW, Tam SF et al. Virtual reality training for stroke rehabilitation. NeuroRehabilitation. 2006;21(3):245-53.

17. Laver K, George S, Ratcliffe J et al. Virtual reality stroke rehabilitationhype or hope? Aust Occup Ther J. 2011;58(3):215-9.

18. Mirelman A, Patritti BL, Bonato P et al. Effects of virtual reality training on gait biomechanics of individuals post-stroke. Gait Posture. 2010;31(4):433-7.

19. Lee HY, Kim YL, Lee SM. Effects of virtual reality-based training and task-oriented training on balance performance in stroke patients. J Phys Ther Sci. 2015;27(6):1883-8.

20. Robert MT, Ballaz L, Lemay M. The effect of viewing a virtual environment through a head-mounted display on balance. Gait Posture. 2016;48:261-6.

21. Laver KE, Lange B, George S et al. Virtual reality for stroke rehabilitation. Cochrane Database Syst Rev. 2017;11:CD008349.

22. Huygelier H, Schraepen B, Van Ee R et al. Acceptance of immersive head-mounted virtual reality in older adults. Sci Rep. 2019;9(1):4519.

23. Faul F, Erdfelder E, Lang AG et al. G*Power 3: a flexible statistical power analysis program for the social, behavioral, and biomedical sciences. Behav Res Methods. 2007;39(2):175-91.

24. Saghaei M. Random allocation software for parallel group randomized trials. BMC Med Res Methodol. 2004;4:26.

25. van Uden CJ, Besser MP. Test-retest reliability of temporal and spatial gait characteristics measured with an instrumented walkway system (GAITRite). BMC Musculoskelet Disord. 2004;5:13.

26. McDonough AL, Batavia M, Chen FC et al. The validity and reliability 
of the GAITRite system's measurements: A preliminary evaluation. Arch Phys Med Rehabil. 2001;82(3):419-25.

27. Lyons DM. System and method for permitting three-dimensional navigation through a virtual reality environment using camera-based gesture inputs. In: Google Patents; 2001.

28. Wang Y, Liu W, Meng X et al. Development of an immersive virtual reality head-mounted display with high performance. Appl Opt. 2016;55(25): 6969-77.

29. Walker ML, Ringleb SI, Maihafer GC et al. Virtual reality-enhanced partial body weight-supported treadmill training poststroke: feasibility and effectiveness in 6 subjects. Arch Phys Med Rehabil. 2010;91(1):115-22.

30. Yang YR, Tsai MP, Chuang TY et al. Virtual reality-based training improves community ambulation in individuals with stroke: a randomized controlled trial. Gait Posture. 2008;28(2):201-6.
31. Pang MY, Eng JJ, Dawson AS. Relationship between ambulatory capacity and cardiorespiratory fitness in chronic stroke: influence of strokespecific impairments. Chest. 2005;127(2):495-501.

32. Ada L, Dean CM, Hall JM et al. A treadmill and overground walking program improves walking in persons residing in the community after stroke: a placebo-controlled, randomized trial. Arch Phys Med Rehabil. 2003;84(10):1486-91.

33. Dunsky A, Dickstein R, Marcovitz E et al. Home-based motor imagery training for gait rehabilitation of people with chronic poststroke hemiparesis. Arch Phys Med Rehabil. 2008;89(8):1580-8.

34. Yang YR, Wang RY, Chen YC et al. Dual-task exercise improves walking ability in chronic stroke: a randomized controlled trial. Arch Phys Med Rehabil. 2007;88(10):1236-40. 